\title{
Unjuk Kerja Motor Bensin Berbahan Bakar Campuran Pertalite dan Pyrolytic Oil dari Pirolisis Kantong Plastik Berkatalis CaO
}

(The Motorcycle Engine Performance Uses A Mixture Of Pertalite And Pyrolytic Oil from The Plastic Pyrolysis Process Using $\mathrm{CaO}$ )

Novi Caroko a, Fiqih Anas Mubaroq ${ }^{b}$, Tito Hadji Agung Santoso ${ }^{c}$, Thoharudin ${ }^{d}$

a, b, c, d Program Studi Teknik Mesin, Fakultas Teknik, Universitas Muhammadiyah Yogyakarta

Jalan Brawijaya, Tamantirto, Kasihan, Bantul, DI Yogyakarta Indonesia, 55183 Telp: +62 274387656 , Faks: +62 274387646

e-mail: fiqihanasmub@gmail.com ${ }^{\mathrm{a}}$, titohas@yahoo.com ${ }^{\mathrm{c}}$, thoharudin@gmail.com ${ }^{\mathrm{d}}$

${ }^{a}$ Pusat Studi Pengelolaan Energi Regional, Universitas Muhammadiyah Yogyakarta

Jalan Brawijaya, Tamantirto, Kasihan, Bantul, DI Yogyakarta Indonesia, 55183

Telp: +62 274387656 , Faks: +62 274387646

e-mail: novicaroko@yahoo.co.id

\begin{abstract}
Abstrak
Penelitian ini bertujuan menguji secara eksperimental pengaruh penggunaan campuran minyak pirolisis dan pertalite pada torsi, tenaga, dan konsumsi bahan bakar motor bensin Honda Beat 110cc. Minyak pirolisis dicampur dengan pertalite dengan persentase volume minyak pirolisis: $0 \%, 5 \%$, $10 \%$, 20\%, dan $30 \%$. Metode yang digunakan dalam penelitian ini adalah menggunakan dynotest tool kit dan fuel consumtion test. Parameter yang diukur adalah nilai torsi, daya, dan konsumsi bahan bakar. Hasil penelitian menunjukkan bahwa pertalite murni menghasilkan torsi dan daya tertinggi dibandingkan dengan variasi campuran pertalite dengan minyak pirolisis lainnya. Hal ini dimungkinkan karena nilai viskositas pertalite lebih rendah dibandingkan dengan variasi lainnya. Konsumsi bahan bakar terendah terdapat pada variasi $70 \%$ volume pertalite dan $30 \%$ volume minyak pirolisis yang menghasilkan konsumsi bahan bakar sebesar $41,66 \mathrm{~km} / \mathrm{l}$.
\end{abstract}

Kata kunci: konsumsi bahan bakar, minyak pirolisis, pertalite, tenaga, dan torsi.

\section{Abstract}

This study aims to experimentally test the effect of using a mixture of pyrolysis oil and Pertalite on torque, power and fuel consumption of the 110cc Honda Beat gasoline motor. Pyrolysis oil is mixed with pertalite with the percentage volume of pyrolysis oil: $0 \%, 5 \%, 10 \%, 20 \%$, and $30 \%$. The method used in this study is to use the dynotest tool kit and fuel consumption test. The parameters measured are the value of torque, power and fuel consumption. The results showed that pure pertalite produced the highest torque and power compared to variations of the pertalite mixture with other pyrolysis oils. This is possible because the pertalite viscosity value is lower compared to other variations. The lowest fuel consumption is found in $70 \%$ volume of pertalite and $30 \%$ volume of pyrolysis oil which results in fuel consumption of $41.66 \mathrm{~km} / \mathrm{l}$.

Keywords: fuel consumption, pertalite, power, pyrolytic oil, and torque.

\section{Pendahuluan}

Produksi sampah plastik di Indonesia mencapai 5,4 juta ton per tahun. Untuk itu, dibutuhkan penanganan yang serius pada masalah sampah plastik ini. Indonesia Solid Waste Association (InSWA) mengajak masyarakat untuk menggunakan plastik ramah 
lingkungan karena keberadaan plastik saat ini sangat mengkhawatirkan [1]. Salah satu solusi yang dapat digunakan pada masalah ini adalah dengan mengubah sampah plastik menjadi bahan bakar alternatif melalui proses pirolisis.

Pirolisis adalah proses pemanasan pada suatu zat tanpa menggunakan oksigen atau sedikit oksigen sehingga mengalami penguraian komponen-komponen penyusun pada kayu kertas. Definisi lain dari pirolisis adalah penguraian yang tidak teratur dari bahan organik yang akan menyebabkan adanya pemanasan tanpa berhubungan dengan udara luar. Hal tersebut mengandung pengertian bahwa apabila plastik dipanaskan tanpa berhubungan dengan udara luar dan diberi suhu tinggi, akan terjadi reaksi penguraian dari senyawasenyawa kompleks yang menyusun kayu kertas dan menghasilkan zat dalam tiga bentuk yaitu padatan, cairan, dan gas [2].

Proses pirolisis limbah plastik dilakukan dengan menggunakan katalis $\mathrm{CaO}$. Proses sintesis $\mathrm{CaO}$ merujuk pada penelitian yang dilakukan oleh Ariawan [3] dengan cara kalsinasi $\mathrm{CaCO} 3$ pada suhu $900^{\circ} \mathrm{C}$ selama 1,5 jam. Untuk mendapatkan katalis $\mathrm{CaO}$ super basa, 12 gram $\mathrm{CaO}$ tersebut dicelupkan ke dalam larutan amonium karbonat berkonsentrasi 0,12 $\mathrm{g} / \mathrm{mL}$ sebanyak $171,5 \mathrm{~mL}$, kemudian diaduk selama 30 menit, dan disaring. Padatan yang terkumpul dipanaskan pada suhu $110^{\circ} \mathrm{C}$ dan dikalsinasi pada suhu tinggi selama 1,5 jam. Setelah dikalsinasi, padatan $\mathrm{CaO}$ dibiarkan mencapai suhu $250^{\circ} \mathrm{C}$ dan dimasukkan ke desikator untuk mencegah terjadinya kontak antara permukaan katalis dan uap air yang mengakibatkan kekuatan basa katalis menurun [4].

Proses pirolisis ini akan menghasilkan minyak dengan nilai kekentalan tinggi sehingga dibutuhkan tambahan bahan bakar yang encer untuk menurunkan nilai viskositasnya. Penelitian ini menggunakan pertalite sebagai bahan bakar campuran dengan minyak hasil pirolisis sampah plastik. Setelah bahan bakar dicampur dengan presentase volume yang telah ditentukan, dilakukan pengujian untuk mengetahui nilai daya dan torsi yang dihasilkan. Uji jalan motor dilakukan untuk mengetahui tingkat konsumsi bahan bakar.

Mustafa [4] melakukan penelitian tentang metode pirolisis menggunakan sampah plastik pada temperatur $900{ }^{\circ} \mathrm{C}$. Uap hasil dari proses pirolisis kemudian dikondensasi melalui crassflow condensor. Proses ini menghasilkan bio oil dengan nilai kalor sebesar $46,848 \mathrm{MJ} / \mathrm{kg}$ yang memiliki arti lebih besar daripada pengolahan sampah plastik suhu 425 ${ }^{\circ} \mathrm{C}$ yaitu sebesar $41.870 \mathrm{MJ} / \mathrm{kg}$. Selain itu, bio oil yang dihasilkan memiliki sifat lebih aman terhadap sifat karsinogenik.

Norsujianto [5] melakukan penelitian limbah plastik yang dipirolisis menjadi bahan bakar minyak dengan menggunakan reaktor tipe Batch bertemperatur $450{ }^{\circ} \mathrm{C}$ yang dialirkan nitrogen dengan kecepatan 0,81/menit. Kemudian pengujian pertama dilakukan, pirolisis ini diuji laboratorium untuk menentukan properties bahan bakar dengan perbandingan campuran 05:95 (blend 5\%), 10:90 (blend 10\%), 15:85 (blend 15\%), 20:80 (blend 20\%). Campuran 10\% WPO memiliki torsi sedikit lebih tinggi daripada biosolar. Campuran 5, 15 dan 20\% memiliki torsi yang identik dengan biosolar, tetapi dengan bertambahnya putaran motor campuran 5\% WPO torsinya kembali lebih rendah. Fenomena adanya nilai torsi maksimum pada putaran tertentu dikarenakan kenaikan torsi akibat kenaikan putaran mesin dibatasi waktu yang tersedia untuk pembakaran pada putaran tinggi semakin singkat dan karena adanya peningkatan rugi-rugi mekanis. Kemudian dilakukan pengujian kedua, pada pengujian ini, minyak pirolisis plastik kemudian diujikan pada motor diesel Engine Research and Test Bed Nissan Diesel SD22 Series tanpa modifikasi. Daya sebagai fungsi dari putaran motor yang dihasilkan oleh campuran 20 dan 10\% sedikit lebih tinggi 0,15 dan 0,29\%. Semakin tinggi putaran mesin, semakin tinggi pula daya yang dihasilkan. Hal ini dipengaruhi oleh kenaikan energi yang dilepas oleh bahan bakar sehingga jumlah bahan bakar yang masuk ke ruang bakar semakin tinggi. Hubungan antara daya dan putaran ini membentuk kurva yang cenderung linier, tetapi apabila dicermati lebih lanjut kurva tersebut membentuk kurva parabolik tertutup yang mempunyai puncak pada suatu nilai tertentu.

Devaraj [6] melakukan penelitian menggunakan limbah plastik yang dipirolisis dengan campuran $5 \%$ dan $10 \%$ dietil eter yang digunakan sebagai bahan bakar pada mesin diesel. Investigasi percobaan tersebut bertujuan mencari nilai unjuk kerja, emisi, dan pembakaran pada mesin diesel. Hasil percobaan menunjukkan penurunan tingkat asap pada mesin dengan minyak hasil pirolisis sampah plastik murni. Berkurangnya senyawa polutan, seperti carbon monoxide (CO) dan nitrous oxide (NOx) karena tereduksi dalam campuran yang menyebabkan nilai brake thermal efficiency (BTE) meningkat. Hasil 
pengujian tersebut mengungkapkan pencampuran diethyl ether dan minyak hasil pirolisis sampah plastik dapat meningkatkan kualitas bahan bakar untuk diesel dan penambahan oksigenat telah meningkatkan proses pembakaran dan mengurangi emisi.

Ilham [7] melakukan penelitian pengujian Dynotest menggunakan motor Yamaha Jupiter-Z 2010 berbahan bakar pertalite dan premium. Hasil penelitian menunjukkan torsi maksimum pada pertalite sebesar 9,11 N.m pada putaran mesin $5128 \mathrm{rpm}$, sedangkan torsi tertinggi yang dihasilkan pada premium sebesar 8,59 N.m pada putaran mesin $4928 \mathrm{rpm}$, sedangkan daya maksimum yang dihasilkan oleh pertalite dan premium sebesar 8,3 HP pada putaran yang bebeda, pertalite pada putaran $7567 \mathrm{rpm}$, dan premium pada putaran $7642 \mathrm{rpm}$. Konsumsi bahan bakar spesifik mengunakan bahan bakar pertalite terendah adalah $0,0170 \mathrm{~kg} / \mathrm{HP}$-jam pada putaran $10000 \mathrm{rpm}$, tertinggi pada $0,0652 \mathrm{~kg} / \mathrm{HP}$-jam pada putaran $4000 \mathrm{rpm}$, diikuti premium nilai spesifik terendah adalah $0,0171 \mathrm{~kg} / \mathrm{HP}$-jam pada putaran $10000 \mathrm{rpm}$, tertinggi pada 0,1061 kg/HP-jam pada putaran $4000 \mathrm{rpm}$.

Saputra [8] melakukan penelitian dengan cara membandingkan konsumsi bahan bakar dari beberapa jenis bahan bakar yang ada di pasaran Indonesia. Penelitian yang dilakukan ini merupakan jenis penelitian ekperimental. Objek utama dalam penelitian ini yaitu membandingkan konsumsi bahan bakar sepeda motor 100cc dengan bahan bakar yang berbeda-beda. Berdasarkan hasil penelitian tersebut, dapat disimpulkan bahwa [1] Bahan bakar premium membutuhkan bahan bakar lebih sedikit daripada bahan bakar pertalite pada semua putaran mesin. [2] Bahan bakar pertalite membutuhkan bahan bakar lebih banyak daripada bahan bakar yang lain pada semua putaran mesin. [3] Bahan bakar pertamax pada putaran bawah lebih boros daripada premium dan pertamax turbo, tetapi pada putaran menengah dan tinggi bahan bakar pertamax lebih irit daripada bahan bakar premium, tetapi masih lebih boros daripada bahan bakar pertamax turbo. [4] Bahan bakar pertamax turbo lebih irit daripada bahan bakar yang lain pada putaran mesin menengah dan tinggi. Namun, pada putaran rendah bahan bakar pertamax turbo lebih boros daripada premium.

\section{MetOde}

Penelitian ini akan menggunakan pyrolytic oil sebagai campuran bahan bakar yang akan dicampur dengan pertalite murni melalui proses pirolis. Agar mendapatkan hasil yang lebih maksimal dan mempercepat laju rekasi pada proses pirolisis, ditambahkan katalis berupa $\mathrm{CaO}$. Setelah mendapatkan pyrolytic oil yang diinginkan, pyrolytic oil tersebut dicampur dengan pertalite murni pada persentase sebesar $0 \%, 5 \%, 10 \%, 20 \%$, dan $30 \%$. Setelah campuran bahan bakar sesuai dengan persentase volume yang ditentukan, kemudian dicari karakteristik dari campuran tersebut meliputi torsi, nilai daya, konsumsi bahan bakar, nilai viskositas, dan nilai kalor.

Proses pengujian dilakukan menggunakan motor bensin dengan merk Honda Beat $110 \mathrm{cc}$ untuk mendapatkan nilai daya, torsi, dan konsumsi bahan bakar. Pengujian konsumsi bakan bakar dilakukan dengan metode uji jalan pada kecepatan $40 \mathrm{~km} / \mathrm{jam}$ dengan jarak uji $5 \mathrm{~km}$. Untuk mendapatkan nilai torsi dan daya, dilakukan pengujian menggunakan dynotest pada putaran mesin 2000-8000 rpm. 


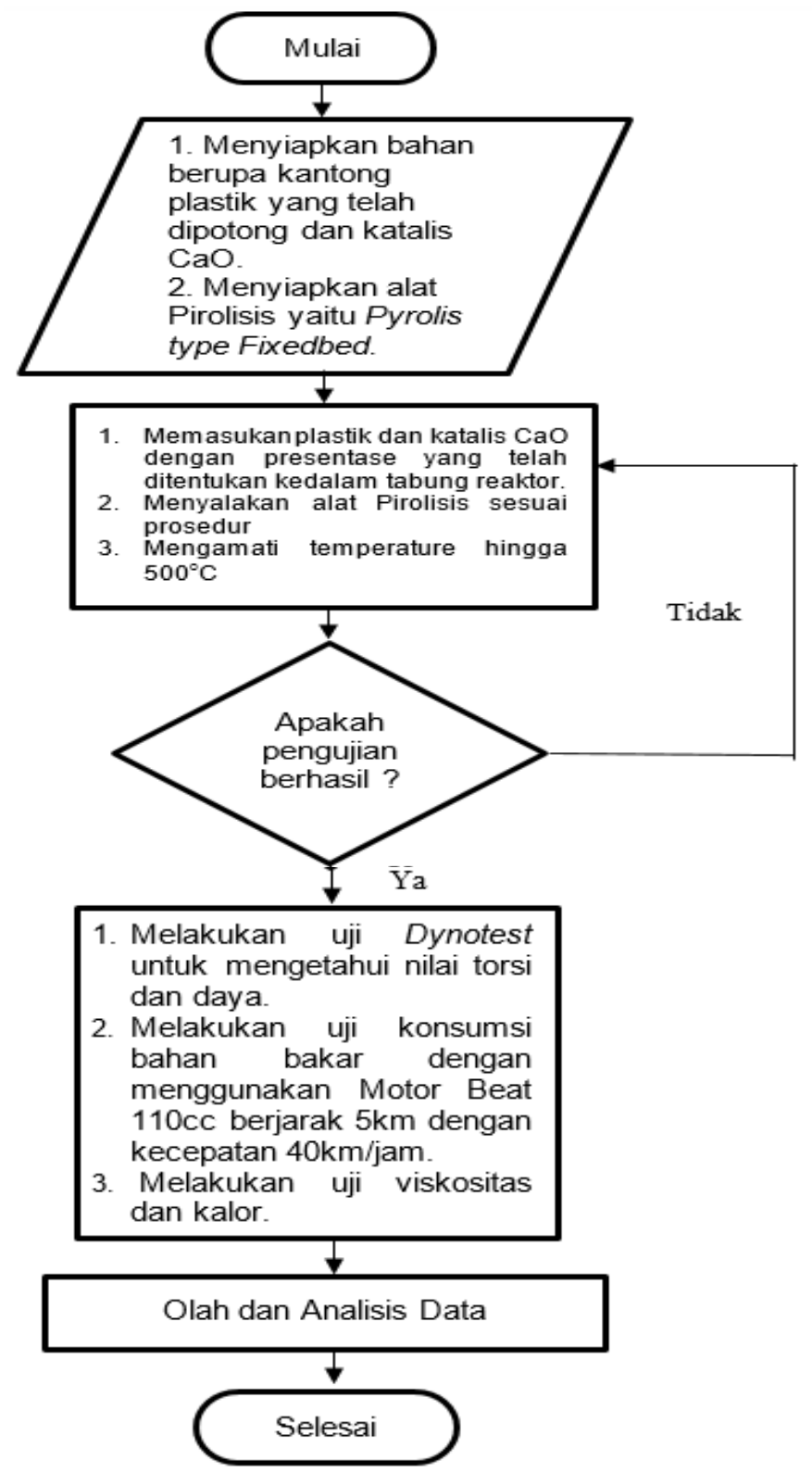

Gambar 2.1. Diagram Alir Metode Penelitian

\section{Hasil dan Pembahasan}

\subsection{Pyrolytic Oil}

Persentase volume campuran antara pertalite murni dan minyak pirolisis dapat dilihat pada tabel 3.1.

Tabel 3.1. Variasi Campuran Pertalite dan Pyrolytic Oil

\begin{tabular}{ccccc}
\hline No & Pertalite $(\mathrm{ml})$ & Pyrolytic Oil $(\mathrm{ml})$ & $\begin{array}{c}\text { Persentase } \\
(\%)\end{array}$ & Total (ml) \\
\hline 1 & 500 & 0 & 0 & 500 \\
2 & 475 & 25 & 5 & 500 \\
3 & 450 & 50 & 10 & 500 \\
4 & 400 & 100 & 20 & 500 \\
5 & 350 & 150 & 30 & 500 \\
\hline
\end{tabular}


Tabel 3.2 memperlihatkan nilai kalor dan viskositas pyrolytic oil tertinggi didapatkan pada komposisi pertalite $70 \%$ vol.-PO $30 \%$ vol. Nilai kalor tertinggi sebesar $34,50 \mathrm{MJ} / \mathrm{kg}$, sedangkan nilai viskositas tertinggi sebesar 2,2 mPa.s. Variasi pertalite $100 \%$ mendapatkan nilai kalor dan viskosotas terkecil yaitu $32 \mathrm{MJ} / \mathrm{kg}$ dan viskositas sebesar $1,1 \mathrm{mPa}$.s. Menurut Juhantoro [9], semakin besar nilai viskositas akan berakibat pada semakin sulitnya proses pengkabutan. Hal ini berpengaruh pada saat proses pembakaran.

Tabel 3.2. Nilai Kalor dan Viskositas Pyrolytic Oil (PO)

\begin{tabular}{lcc}
\hline \multicolumn{1}{c}{ Jenis bahan bakar } & $\begin{array}{c}\text { Nilai Kalor } \\
\text { (MJ/kg) }\end{array}$ & $\begin{array}{c}\text { Nilai Viskositas } \\
\text { (mPa.s) }\end{array}$ \\
\hline Pertalite 100\% & 32 & 1,1 \\
Pertalite 95\%vol. -PO 5 \%vol. & 31,570 & 1,2 \\
$\begin{array}{l}\text { Pertalite 90 \%vol. - PO 10\% } \\
\text { vol. }\end{array}$ & 32,89 & 1,2 \\
$\begin{array}{l}\text { Pertalite } 80 \text { \%vol. -PO } 20 \\
\text { \%vol. }\end{array}$ & 34,47 & 1,6 \\
$\begin{array}{l}\text { Pertalite } 70 \text { \%vol. -PO } 30 \\
\text { \%vol. }\end{array}$ & 34,50 & 2,2 \\
\hline
\end{tabular}

\subsection{Torsi}

Gambar 3.1. memperlihatkan bahwa pengujian nilai torsi memiliki titik tertinggi pada semua variasi pengujian. Dari semua hasil pengujian, dapat diketahui bahwa hasil tertinggi diperoleh pada variasi pertalite 95\%vol.-PO 5\%vol. dengan nilai torsi $27,65 \mathrm{~N} . \mathrm{m}$ pada putaran mesin $1861 \mathrm{rpm}$. Pada saat awal proses pengujian, nilai torsi yang diperoleh berbeda antara variasi satu dengan yang lain, tetapi pada putaran mesin mencapai 4000 rpm grafik nilai torsi cenderung berhimpitan. Hal tersebut disebabkan saat awal gas terjadi peningkatan konsumsi bahan bakar ke dalam silinder.

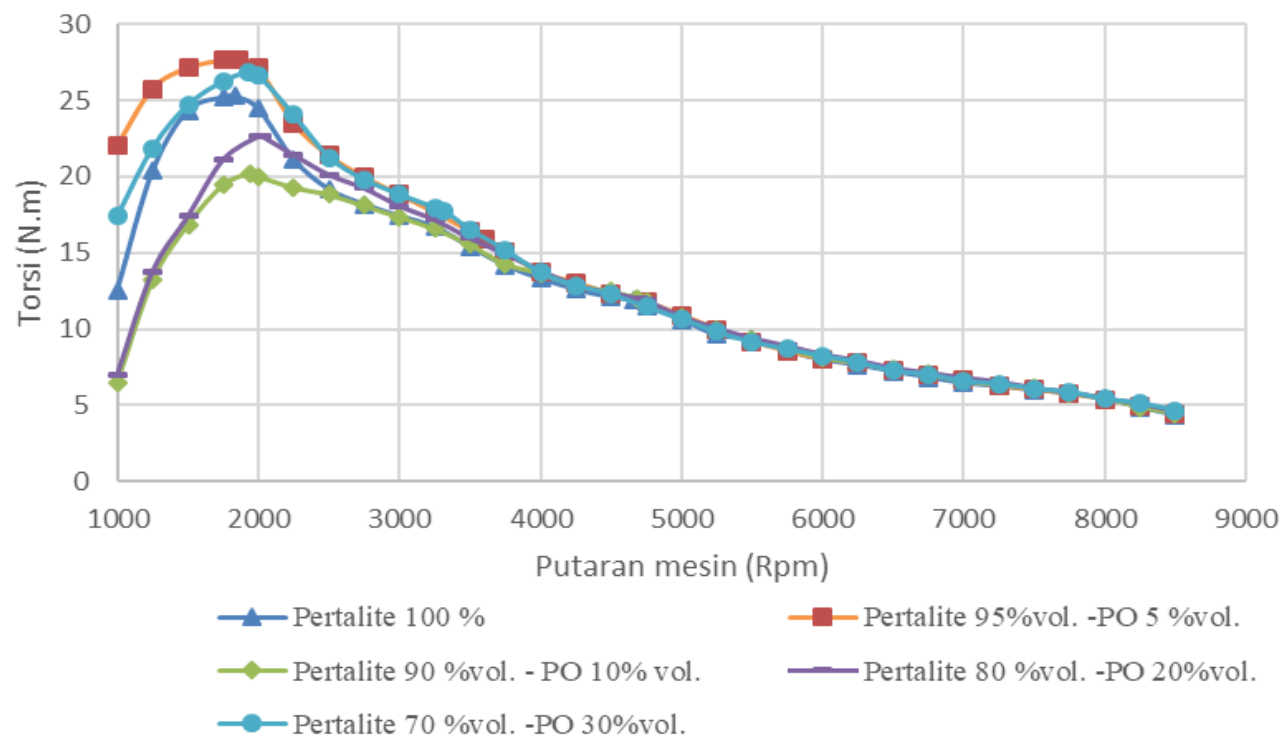

Gambar 3.1. Perbandingan Putaran Mesin (rpm) dengan nilai Torsi (N.n)

\subsection{Daya}

Gambar 3.2 menunjukan nilai daya. Dari data tersebut, didapatkan nilai titik daya tertinggi terdapat pada variasi pertalite $95 \%$ vol. $-5 \%$ vol. dengan nilai sebesar $8,2 \mathrm{HP}$ pada putaran mesin $4667 \mathrm{rpm}$. Nilai daya berkaitan dengan besarnya nilai torsi, semakin besar 
nilai torsi yang dihasilkan, semakin besar juga nilai daya yang didapat. Penurunan daya yang lebih lambat daripada penurunan torsinya dikarenakan kenaikan nilai putaran yang lebih tinggi dari penurunan nilai torsinya sehingga meskipun torsi sudah menurun, dayanya masih naik sebelum akhirnya turun mengikuti torsi.
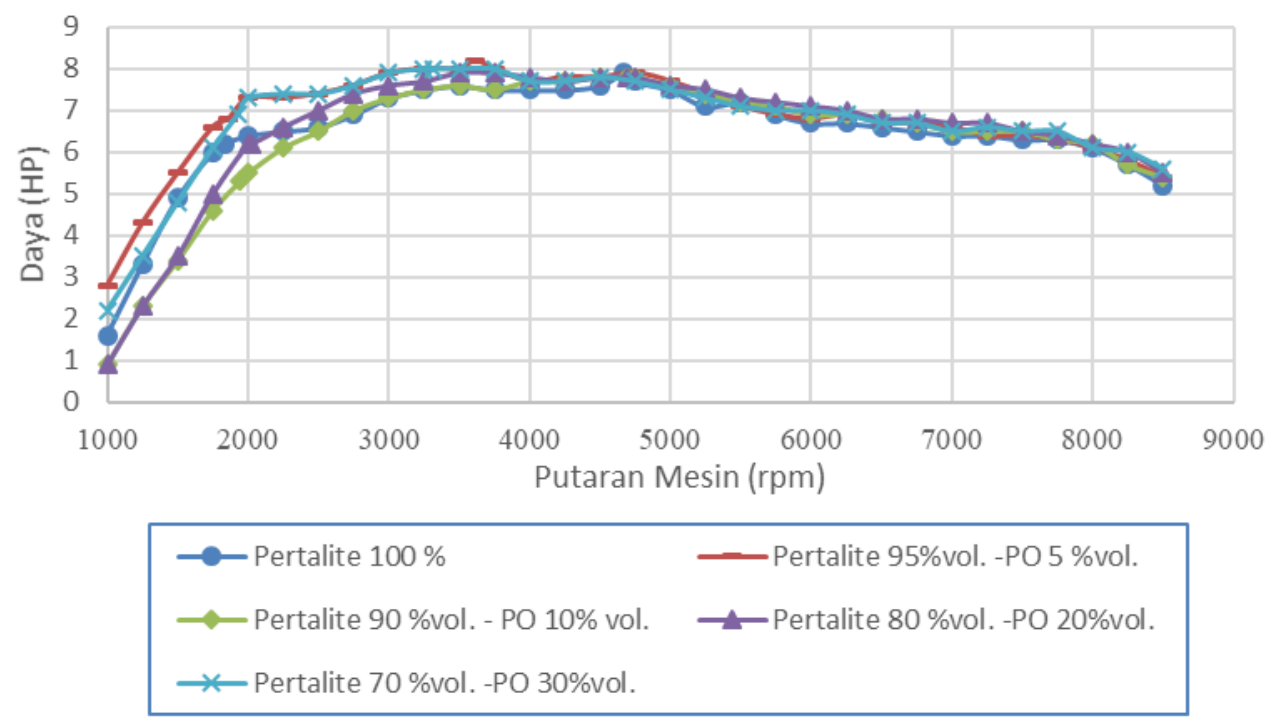

Gambar 3.2. Perbandingan Nilai Putaran Mesin dengan Nilai Daya (HP)

\subsection{Konsumsi Bahan Bakar}

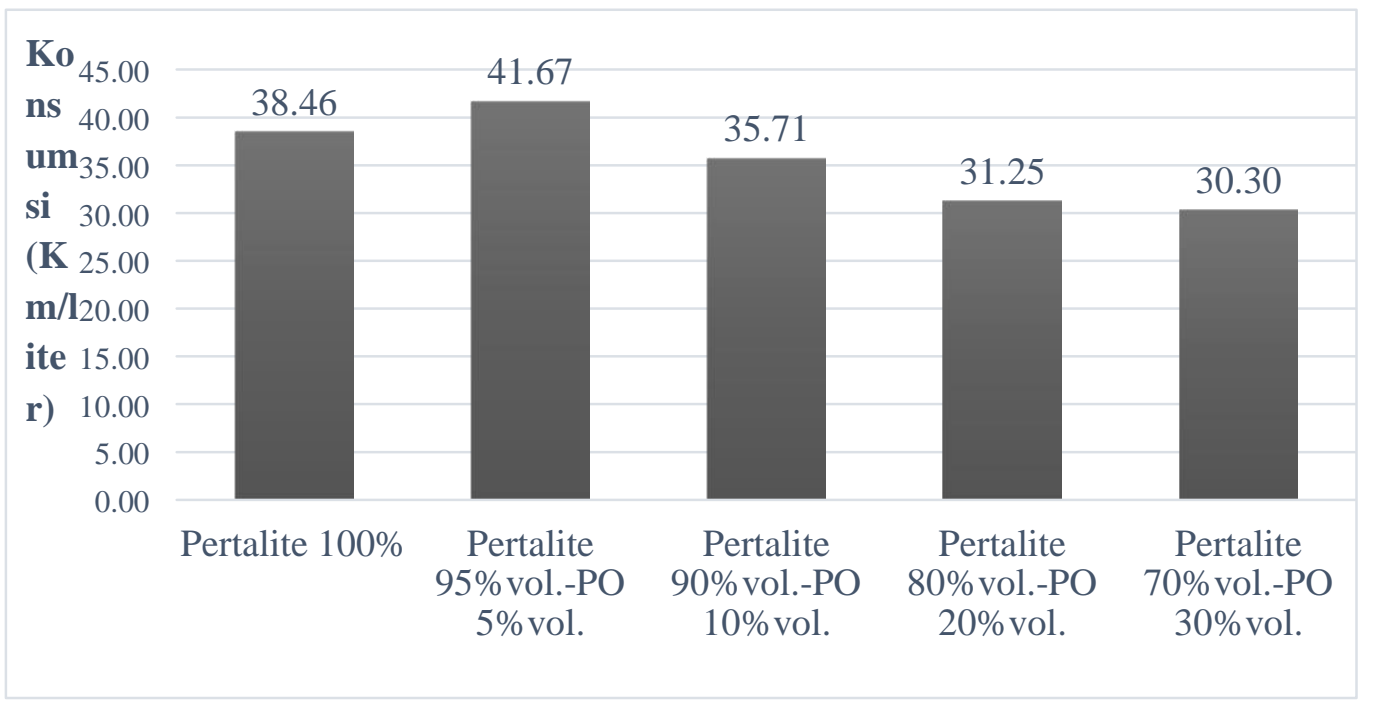

Gambar 3.3. Perbandingan Konsumsi Bahan Bakar

Pada Gambar 3.3, dapat dilihat bahwa konsumsi bahan bakar yang tertinggi atau teririt terdapat pada bahan bakar campuran pertalite dengan PO $5 \%$ yang memiliki nilai torsi dan daya yang melebihi nilai dari variasi lainnya. Menurut Mulyono dkk. [10], besarnya nilai konsumsi bahan bakar dipengaruhi oleh viskositas, nilai viskositas yang tinggi akan menyebabkan bahan bakar sulit terbakar yang berdampak pada konsumsi bahan bakar akan meningkat. Namun pada penelitian ini, diungkapkan bahwa jika bahan bakar terlalu besar nilai viskositasnya, bahan bakar tersebut akan terlalu sulit untuk dibakar sehingga performa pada mesin akan menurun. 


\section{KesimpULAN}

Berdasarkan hasil pengujian yang dilakukan, dapat diketahui bahwa nilai torsi dan nilai daya yang paling ideal terdapat pada variasi bahan bakar campuran pertalite $95 \%$ dan PO $5 \%$ dengan nilai torsi sebesar 27,65 N.m pada kecepatan putaran mesin $1861 \mathrm{rpm}$. Nilai daya terbesar pada pengujian ini berada pada nilai 8,2 HP dengan kecepatan putaran mesin $3611 \mathrm{rpm}$ menggunakan variasi bahan bakar campuran pertalite 95\% dan PO 5\%.

Konsumsi bahan bakar tertinggi terdapat pada variasi bahan bakar pertalite $70 \%$ vol -PO $30 \% \mathrm{vol}$ dengan konsumsi bahan bakar sebesar 30,30 km/l, sedangkan konsumsi bahan bakar terendah atau terhemat terdapat pada variasi bahan bakar pertalite $95 \%$ vol - PO $5 \% \mathrm{vol}$ dengan konsumsi sebesar $41,66 \mathrm{~km} / \mathrm{l}$. Konsumsi bahan bakar berbanding lurus dengan nilai torsi dan daya.

\section{Daftar Pustaka}

[1] Ningrum AO. Proses Pembuatan Biooil Dari Limbah Kelapa Sawit Untuk Bahan Bakar Alternatif. Skripsi. Jakarta: Universitas Indonesia, Fakultas Teknik; 2011.

[2] R. Ahmad, N. Hamidin, U.F.M. Ali , C.Z.A. Abidin. Characterization Of Bio-Oil From Palm Kernel Shell Pyrolysis. Journal of Mechanical Engineering and Sciences (JMES). 2014; 7: p. 2231-8380.

[3] I Wayan Budi Ariawan, I.G.B Wijaya Kusuma, I.W Bandem Adnyana. Pengaruh Penggunaan Bahan Bakar Pertalite Terhadap Unjuk Kerja Daya, Torsi Dan Konsumsi Bahan Bakar Pada Sepeda Motor Bertransmisi Otomatis. METTEK. 2016; 2: p. 51 - 58.

[4] Mustafa M. Pengaruh Campuran Bahan Bakar Bensin Terhadap Prestasi Mesin Bensin. Arika. 2014; 5: p. 138-146.

[5] Norsujianto, T.. Unjuk Kerja Dan Emisi Gas Buang Motor Diesel Menggunakan Bahan Bakar Campuran Minyak Hasil Pirolisis Limbah Plastik Dan Biosolar Sebagai Bahan Bakar Alternatif.. Teknologi dan Industri. 2014; 3: p. 24-32.

[6] Devaraj, J., Robinson, Y. \& Ganapathi, P. Experimental Investigation of Performance, Emission And Combustion Characteristics of Waste Plastic Pyrolysis Oil Blended With Diethyl Ether Used As Fuel For Diesel Engine. Energy. 2015; 85: p. 304-309.

[7] Ilham M. Pengaruh Bahan Bakar Pertalite Dan Premium Terhadap Performa Mesin Motor Yamaha Jupiter Z-Cw Tahun 2010. Pontianak. 2008.

[8] Saputra, Onery Andy. Pengaruh Jenis Bahan Bakar Motor Bensin Dengan Tingkat Konsumsinya. AUTINDO Politeknik Indonusa Surakarta. 2017; 1.

[9] Nanang Juhantoro, I Made Ariana dan Semin Sanuri. Penentuan Properties Bahan Bakar Batubara Cair untuk Bahan Bakar Marine Diesel Engine. Jurnal Teknik ITS. 2012; 1: p. 271 .

[10] Sugeng Mulyono, Gunawan, Budha Maryantu. Pengaruh Penggunaan dan Perhitungan Efisiensi Bahan Bakar Premium dan Pertamax Terhadap Unjuk Kerja Motor Bakar Bensin. Jurnal Teknologi Terpadu. 2014; 2. 